TITLE:

\title{
A possible stress interaction between large thrust and normal faulting earthquakes in the Mexican subduction zone
}

\section{$\operatorname{AUTHOR}(S)$ :}

Mikumo, Takeshi; Singh, Shri Krishna; Santoyo, Miguel A.

\section{CITATION:}

Mikumo, Takeshi ... [et al]. A possible stress interaction between large thrust and normal faulting earthquakes in the Mexican subduction zone. Bulletin of the Seismological Society of America 1999, 89(6): 1418-1427

\section{ISSUE DATE:}

1999-12

URL:

http://hdl.handle.net/2433/193407

\section{RIGHT:}

(C) 1999, by the Seismological Society of America 


\title{
A Possible Stress Interaction between Large Thrust and Normal Faulting Earthquakes in the Mexican Subduction Zone
}

\author{
by Takeshi Mikumo, Shri Krishna Singh, and Miguel A. Santoyo
}

\begin{abstract}
A large, nearly vertical, normal-faulting earthquake $\left(M_{\mathrm{w}}=7.1\right)$ took place in 1997 in the subducting Cocos plate just beneath the ruptured fault zone of the 1985 Michoacan, Mexico, earthquake $\left(M_{\mathrm{w}}=8.1\right)$. We investigate the possibility of stress interaction between the two large events through a $3 \mathrm{D}$ analysis of coseismicstress change that was due to the first event, taking into consideration the postseismic change and the dynamic rupture process of the second event. In the middle portion of the subducting plate at depths below $30 \mathrm{~km}$, the calculated coseismic increase in the vertical-shear stress and in the Coulomb-failure stress beneath the high stressdrop zones of the 1985 earthquake is in the order of 0.4 to $0.8 \mathrm{MPa}$. It was also found that the 1997 earthquake took place in the zone of maximum coseismic-stress increase. Possible postseismic-stress changes due to the subduction process or to the loading of the overriding continental lithosphere and from aseismic slip would enhance the coseismic-stress change and hence the possibility of occurrence of a normal-faulting earthquake in the subducting plate. The dynamic rupture pattern of the 1997 event seems to be consistent with the inferred stress interactions.
\end{abstract}

\section{Introduction}

A large, nearly vertical, normal-faulting earthquake $\left(M_{\mathrm{w}}=7.1\right)$ occurred on 11 January 1997 beneath the Michoacan segment of the Mexican subduction zone (Santoyo et al., 1999). Although intermediate-depth, normal-faulting events occur relatively frequently in the Cocos plate, which subducts beneath the Mexican continent (e.g. Singh et al., 1985; Pardo and Suarez, 1995; Cocco et al., 1997), the location of the present earthquake is quite unusual because it took place just beneath the extensively ruptured fault zone of the great 1985 Michoacan, Mexico earthquake $\left(M_{\mathrm{w}}=8.1\right)$ on 19 September 1985 .

Large lithospheric normal-faulting earthquakes also occur in several other subduction zones: Sanriku (Kanamori, 1971) and Shioya-oki (Abe, 1977), northeastern Japan, west Shikoku (Shiono and Mikumo, 1975), Mariana (Yoshida et al., 1992), Rat Islands, Aleutian (Abe, 1972a), northern Peru (Abe, 1972b), northern Chile (Kausel and Campos, 1992); Sumba (Spence, 1986; Lynnes and Lay, 1988), and Tonga (Eissler and Kanamori, 1982; Spence, 1986; Christensen and Lay, 1988; Lundgren and Okal, 1988). Most of the aforementioned earthquakes that occurred in a partially decoupled plate were interpreted to be caused by tensile stress due to the gravitational pull of the denser subducting slab, rupturing nearly the entire plate thickness. Some of these reported events took place in the updip portion of the slab a few days to several years after a large thrust earthquake, which seems to have ruptured the coupled interface. In the Mexican sub- duction zone, on the other hand, some normal-faulting earthquakes took place in the downdip portion up to ten years following the occurrence of large shallow-thrust events (Singh et al., 1985; Cocco et al., 1997). However, the causal relationship between the two types of earthquakes, if any, is not well understood (Singh et al., 1985).

The 1997 earthquake with a nearly vertical fault plane (Santoyo et al., 1999) was located right below the ruptured zone of the 1985 large-thrust event (Fig. 1a, b), while other normal-faulting earthquakes took place near the trench or the outer rise farther updip of the thrust plane, or some far downdip. The goal of the present study is to find if there is any possible stress interaction between the two recent earthquakes in the Mexican subduction zone. We apply a 3D stress analysis and make some qualitative considerations on possible postseismic stress changes. We will show that the stress transfer from the 1985 earthquake down to the subducting plate could be one of possible sources that enhance the possibility of occurrence of the 1997 earthquake.

\section{Model and Method of Calculations}

One useful method to investigate a possible stress interaction between any two events is to estimate the coseismic stress change caused by the first event near the fault zone of the second event and its postseismic change up to the time of the latter event. 
(a)

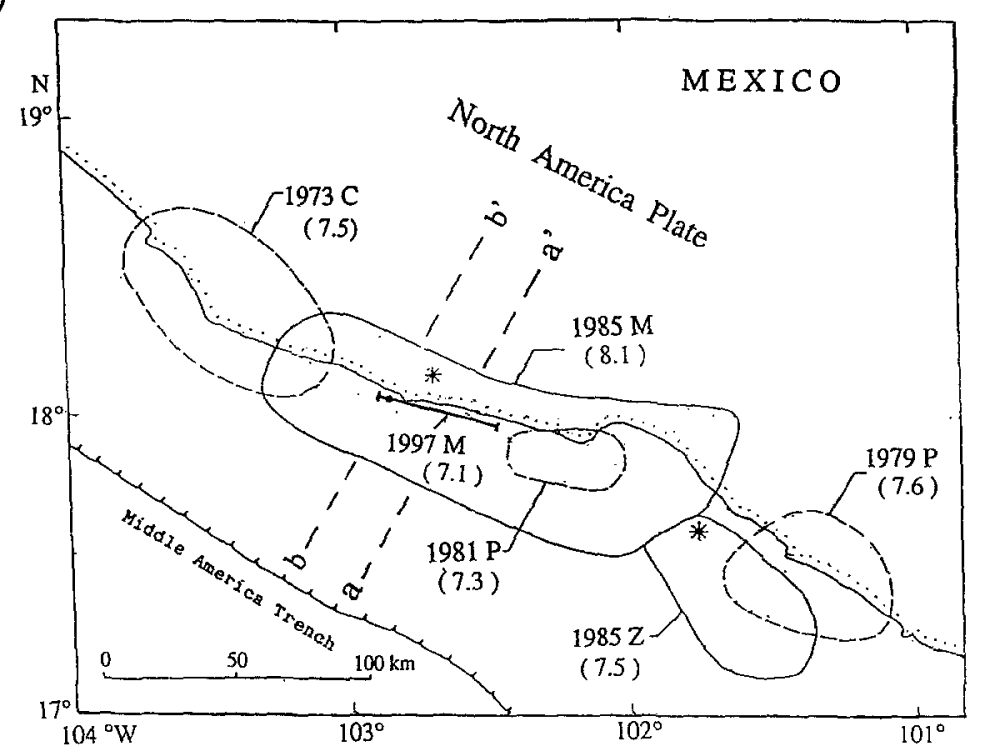

Figure 1. (a) Location of the 1997 earthquake (Santoyo et al., 1999) and the aftershock areas of recent large earthquakes in the Michoacan-Guerrero regions of Mexico (modified from UNAM Seismology Group, 1986). Their magnitudes in parentheses are given in $M$ s. (b) Schematic side view of the 1985 thrust event and the 1997 normal fault, which are indicated by bold lines, with respect to the subducting Cocos plate and the overlying continental crust (C.C.) and uppermost mantle (U.M.). The velocity and density structures with layer indices are given in Table 1 .

(b)

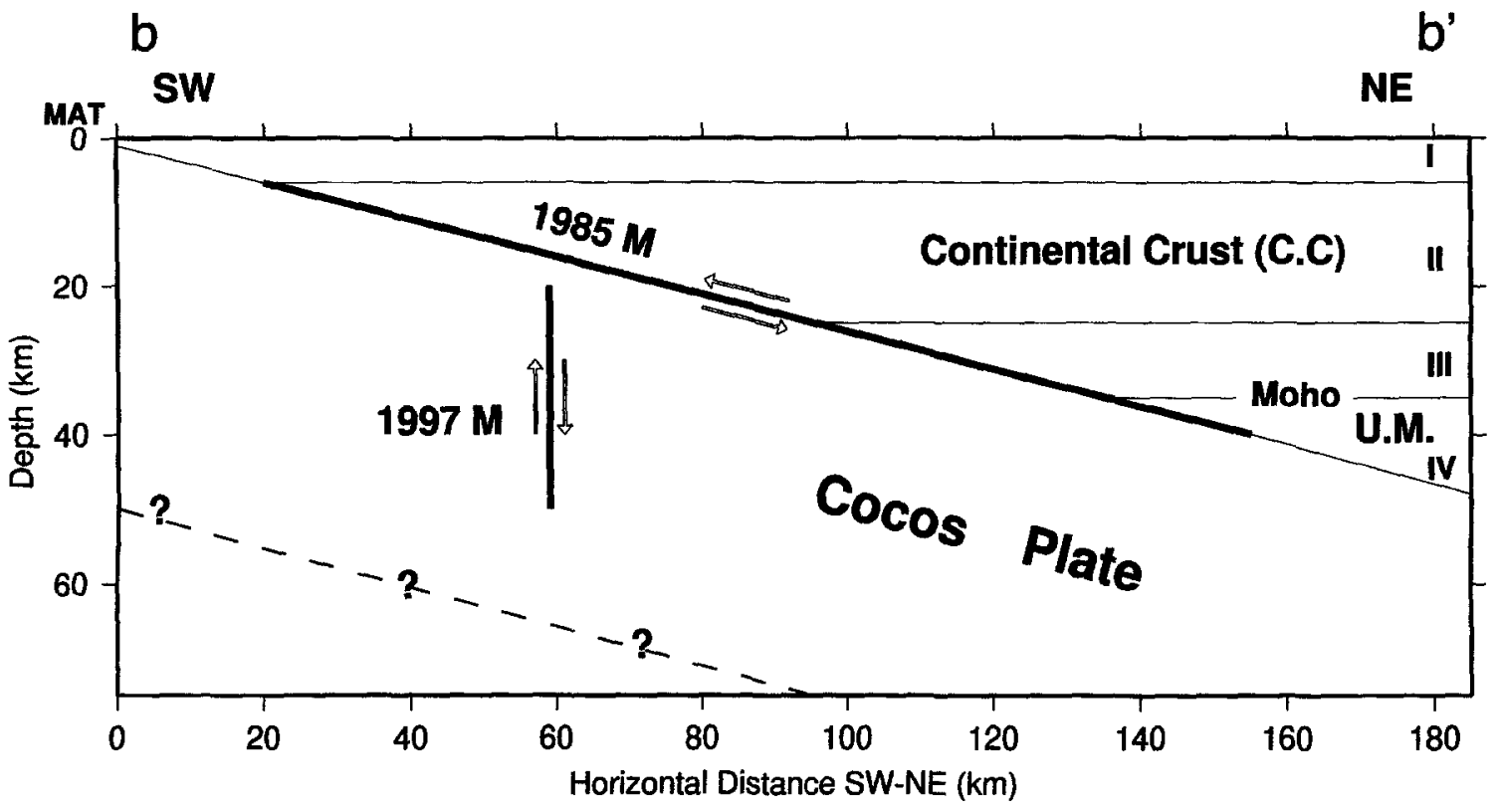

We calculate here the coseismic change of all stress components due to the 1985 thrust earthquake, not only on the fault but in the subducting plate and the overlying continental crust and uppermost mantle. The model used here is an extension of a 3D dynamic-rupture model (Mikumo et al., 1998) and incorporates a shallow-dipping fault located above the subducting plate, which is embedded in a horizontally layered half-space (Fig. 2a, b). The method of calculation essentially follows the previous approach (Mikumo and Miyatake, 1993; Mikumo et al., 1998). In this method, all displacement and stress components in the 3D model space and dynamic-rupture propagation on the fault are calculated by solving elastodynamic equations under appropriate boundary conditions, with a second-order finite-differ- ence scheme. We assume that the initial shear stress is applied parallel to the dipping fault (see Figure $2 b$ ) and that it gradually increases due to the approach of the rupture front and drops immediately to the level of dynamic friction at the time of rupture arrival, when it exceeds the prescribed peak stress level. The difference between the initial and final stresses is taken as static-stress drop. The boundary conditions to be satisfied are (1) the continuity of the normal stress and displacement components across the fault, (2) the traction-free ground surface, (3) the continuity of all stress and displacements components at each of the layer interfaces, and (4) absorbing boundary conditions (Clayton and Engquist, 1977) at the side and the bottom boundaries of the model space. 
(a)

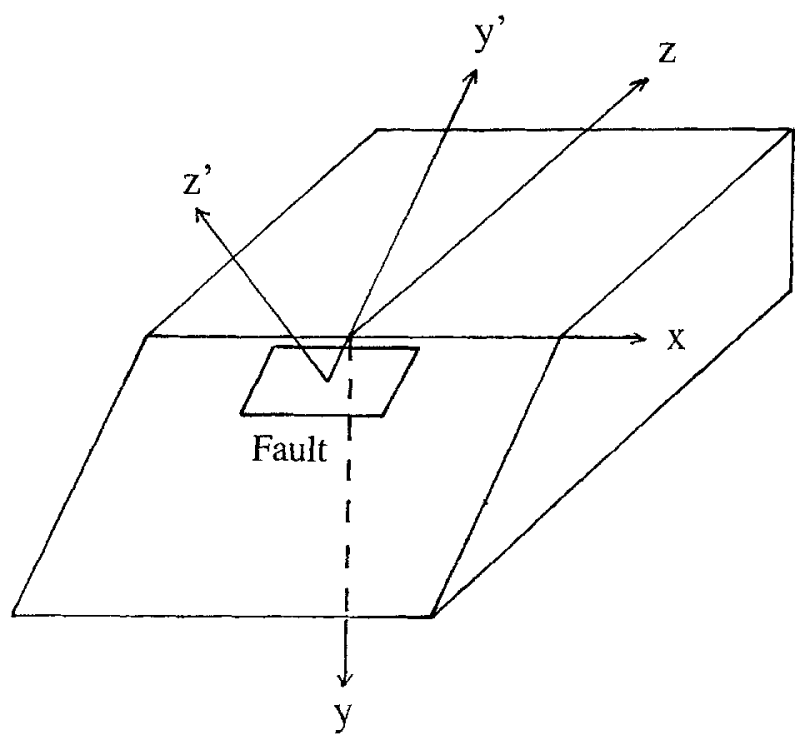

Figure 2. (a) Location of a dipping fault and the 3D model used here with the coordinate axes illustrated. (b) Side view of the 3D model space incorporating a horizontally layered-velocity structure (modified from Mikumo and Miyatake, 1993).

(b)

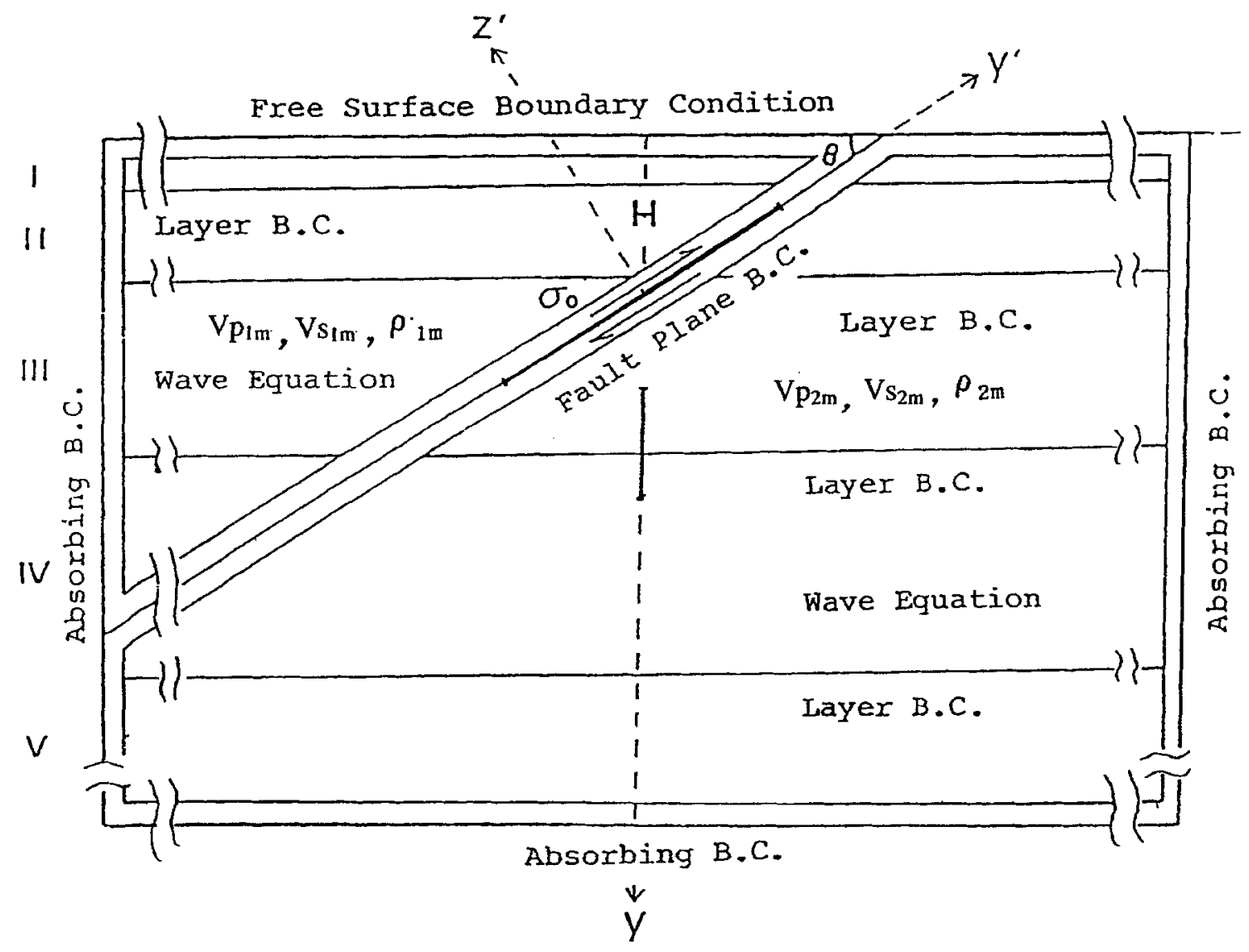

To evaluate the spatial distribution of dynamic- and static-stress changes, we use a nonlinear, iterative leastsquares technique by incorporating some of the kinematic fault parameters as observational constraints. Given approximate estimates of static-stress drop on the fault plane as starting values, we calculate the distribution of fault slips from the above dynamic model and compare them with the previously obtained kinematic slips. The ratio between the kinematic and dynamic slips at each point on the fault is then multiplied to the previously estimated stress drop in the next iteration. This procedure is repeated until the rms difference between the kinematic and dynamic slips over the 
fault can be minimized within a reasonably small value, which gives a best-fitting model. The distribution of dynamic- and static-stress changes on the fault as well as in the model space are obtained from the final model. (For more details, see Mikumo and Miyatake, 1993; Mikumo et al., 1998).

The spatial distribution of dynamic- and static-stress drops over the fault plane of the 1985 Michoacan thrust earthquake has been evaluated (Mikumo et al., 1998) in this way from the distribution of kinematic fault slip (Mendoza and Hartzell, 1989) based on waveform inversion of strongmotion records. The present calculation, incorporating the same observations, uses a finer grid spacing $(5.0 \mathrm{~km}$ on the fault, $1.25 \mathrm{~km}$ in the vertical direction, and $4.85 \mathrm{~km}$ in the horizontal direction for a fault dip of $14^{\circ}$ ). The extent of the 3D model space is taken as $350 \mathrm{~km} \times 105 \mathrm{~km} \times 240$ $\mathrm{km}$ in the $\mathrm{x}, \mathrm{y}$, and $\mathrm{z}$ directions, respectively (Fig. 2).

The crust and uppermost mantle structure assumed here is taken from a 3-layer velocity model (Mendoza and Hartzell, 1989) which is given in Table 1 . Since this model has been used by Mendoza and Hartzell to derive the distribution of kinematic slips on the 1985 earthquake fault, we also use it in calculating the corresponding stress change. However, a more refined structure in the Michoacan region (Valdes and Meyer, 1996) shows slightly higher velocities (5-10\%) in the subducting Cocos plate overriden by oceanic crusts with slightly lower velocities. For this reason, we performed the present calculations by assuming elastic wave velocities and densities which are 0,5 , and 10\% higher in the subducting slab than in the overlying crust and uppermost manthe at the same layer (Table 1, Figs $1 b$ and $2 b$ ). The effects of this velocity contrast on our results are described in the next section. The results shown in the figures that follow correspond to the first case.

\section{Results}

Although the calculation provides dynamic changes of all stress components during the rupture process of the 1985 event, here we are looking only at the final values (i.e., staticstress changes) of four stress components (see Figure 2 for the coordinate system); $\Delta \sigma_{y^{\prime} z^{\prime}}$ (shear stress along the dipping fault), $\Delta \sigma_{y^{\prime} y^{\prime}}$ (compressional stress along the direction parallel to the fault), $\Delta \sigma_{\mathrm{yz}}$ (shear stress in the vertical direction), and $\Delta \sigma_{\mathrm{zz}}$ (horizontal tensional stress). The value $\Delta \sigma_{\mathrm{yz}}$ corresponds to the change in shear stress due to the 1985 event, resolved into the vertical-fault direction of the 1997 event, and $\Delta \sigma_{z z}$ corresponds to the change in normal stress due to the 1985 event in the direction perpendicular to the 1997 fault. These two components constitute the well-known Coulomb stress $\Delta \sigma_{\text {cfs }}=\Delta \sigma_{y z}+\mu^{\prime} \Delta \sigma_{z z}$, where $\mu^{\prime}$ is the apparent coefficient of friction for the effective confining pressure, that is, the difference between the normal stress and the fluid-pore pressure (King et al., 1994). Since the most appropriate value of $\mu^{\prime}$ is still not well known, we take three different values of $\mu^{\prime}=0.0,0.4$, and 0.6 . In the case
Table 1

Crust and Uppermost Mantle Velocity Model used in This Study (after Mendoza and Hartzell, 1989)

\begin{tabular}{cccccc}
\hline Layer $(\mathrm{m})$ & $H(\mathrm{~km})$ & $V_{\mathrm{P}}(\mathrm{km} / \mathrm{seec})$ & $V_{\mathrm{S}}(\mathrm{km} / \mathrm{sec})$ & $\rho\left(\mathrm{g} / \mathrm{cm}^{3}\right)$ & $c_{\mathrm{m}}$ \\
\hline I & 0 & 5.80 & 3.35 & 2.68 & $1.00,1.05,1.10$ \\
II & 6 & 6.40 & 3.69 & 2.78 & $1.00,1.05,1.10$ \\
III & 25 & 7.00 & 4.04 & 2.85 & $1.00,1.05,1.10$ \\
IV & 35 & 8.00 & 4.62 & 3.00 & $1.00,1.05,1.10$ \\
\hline
\end{tabular}

$\mathrm{m}$, layer index number; $H$, top depth of the $\mathrm{m}$-th layer; $\mathrm{V}_{\mathrm{P}}, P$-wave velocity; $V_{\mathrm{S}}, \quad$ S-wave velocity; $\rho$, density; $c_{\mathrm{m}}=V_{\mathrm{P}_{2 \mathrm{~m}}} / V_{\mathrm{P}_{1 \mathrm{~m}}}=$ $V_{\mathrm{S}_{2 \mathrm{~m}}} / V_{\mathrm{S}_{1 \mathrm{~m}}}=\rho_{2 \mathrm{~m}} / \rho_{1 \mathrm{~m}}$ (1 and 2 correspond to the portions of the overlying crust and uppermost mantle and the subducting slab, respectively.)

of $\mu^{\prime}=0, \Delta \sigma_{\mathrm{cfs}}=\Delta \sigma_{\mathrm{yz}}$. The Coulomb failure stress criterion has been widely used to predict possible regions of subsequent failure and aftershock locations of crustal earthquakes, as recently summarized by Harris (1998).

Figure 3 shows the distribution of stress change $\Delta \sigma_{y^{\prime} z^{\prime}}$ over the fault plane $\left(180 \mathrm{~km} \times 140 \mathrm{~km}\right.$, dipping at $14^{\circ}$ toward north-northeast) of the 1985 earthquake. Four high stress-drop (stress decrease) zones corresponding to the rupture of existing asperities can be identified; two of them are located in the relatively shallow fault section, and the other two are in the deeper part. The maximum stress drop exceeds 130 bars. The negative stress drop (coseismic stress increase) zone spreads around and in between the high stress-drop zones. The coseismic stress change $\Delta \sigma_{y^{\prime} z^{\prime}}$ on two vertical profiles, $\mathbf{a}-\mathbf{a}^{\prime}$ and $\mathbf{b}-\mathbf{b}^{\prime}$ in Figures $1 \mathrm{a}$ and $\mathbf{3}$ is shown in Figure 4. The profiles $a-a^{\prime}$ and $b^{-} b^{\prime}$ go across the portion of the maximum stress drop on the 1985 fault and the hypocenter of the 1997 earthquake, respectively. Note that this shear stress component decreases below and above the upper half of the dipping fault both in the subducting slab and in the overlying crust, while it increases below some depth in the middle portion of the slab and also near the updip and downdip portions of the plate interface. These patterns are similar for the two profiles. Figure 5 gives coseismic change $\Delta \sigma_{y^{\prime} y^{\prime}}$ along the two profiles, which clearly shows, as expected, the zones of compressional stress increase updip above the thrust plane and in the middle and downdip below the plane, while the zone of stress decrease can be recognized updip below the thrust plane and downdip above the plane.

The coseismic changes in shear stress $\Delta \sigma_{\mathrm{yz}}$ and in the Coulomb failure stress $\Delta \sigma_{\text {cfs }}\left(\mu^{\prime}=0.4\right)$ along the two profiles are shown in Figure 6a and $b$. The patterns of their distribution are quite similar to those in Figure 4 and are mainly characterized by three zones of stress increase and stress decrease, which appear to be separated by several lobes. Small bumps seen in zero contours may be due to less accuracy of the second-order finite-difference calculations near the contours.

The most remarkable feature is that the shear stress and the Coulomb stress increase in the subducting slab below a depth of about $30 \mathrm{~km}$ just beneath the high stress-drop zone of the 1985 thrust event (indicated hereafter by P-zone), 


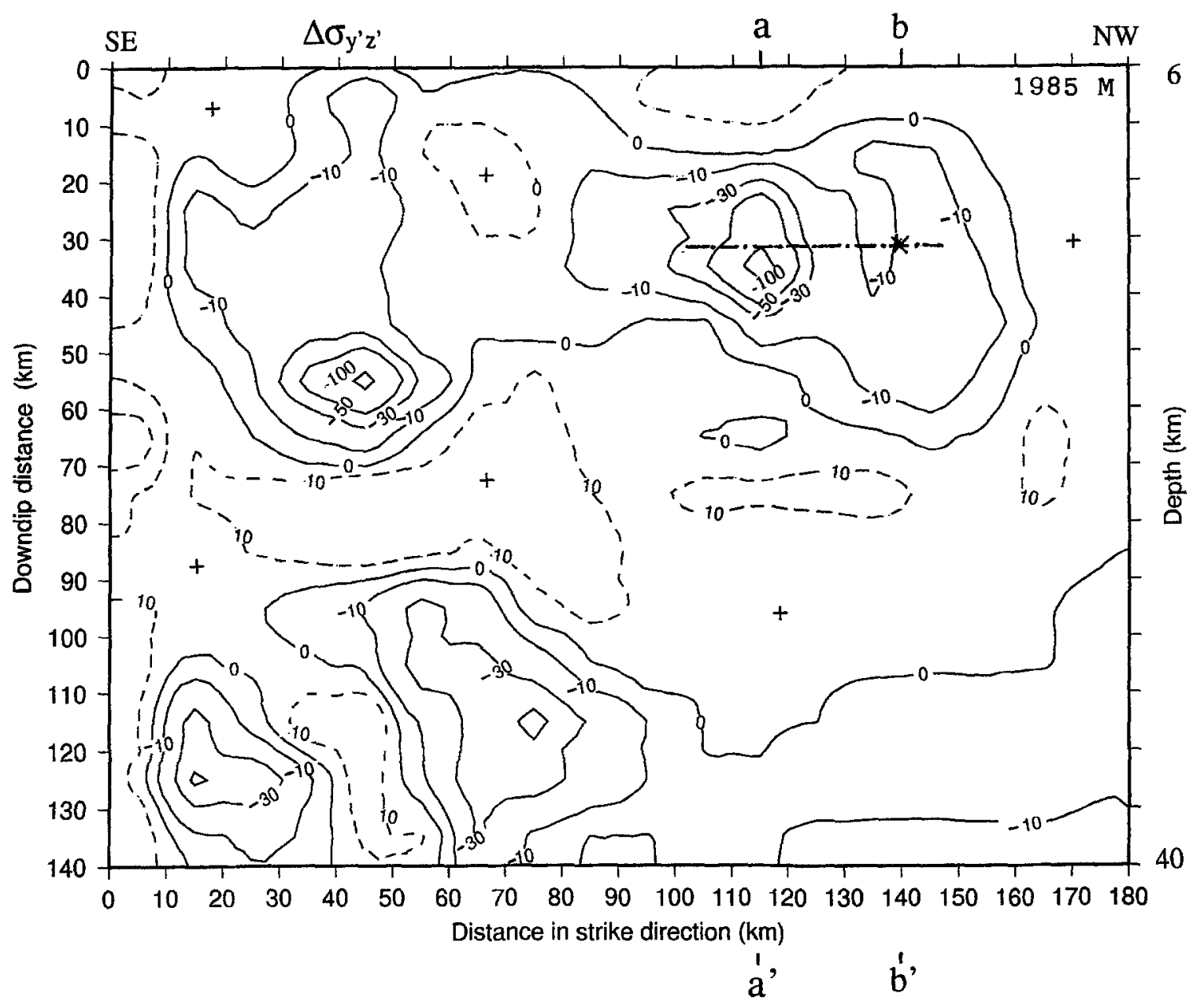

Figure 3. Distribution of the calculated shear stress drop $\Delta \sigma_{y^{\prime} z^{\prime}}$ (in bars) on the fault plane of the 1985 thrust earthquake. Full and broken contours indicate stress decrease and increase, and plus sign denotes the zone of stress increase, respectively. A chain line at a downdip depth of about $30 \mathrm{~km}$ shows the location of the 1997 vertical fault projected onto the 1985 thrust fault plane. An asterisk indicates the hypocentral location of the 1997 event. Two profiles $a-a^{\prime}$ and $b-b^{\prime}$ are taken to pass through the region of the maximum stress drop and and the hypocenter of the 1997 earthquake.

while the zone of stress decrease obliquely extends down below its updip and downdip portions of the slab. Zones of stress increase also exist near the updip and downdip portions. Incidentally, these patterns are quite similar to those for the failure stress calculated for shallow dipping thrust earthquakes in the upper crust (Freed and Lin, 1998). The maximum magnitude of coseismic stress increase in the Pzone in the middle portion of the subducting slab reaches 8 bars for the profile a-a' (Fig. 6a) and about 4 bars in the b$\mathrm{b}^{\prime}$ profile (Fig. $6 \mathrm{~b}$ ). The magnitudes do not change significantly for the two cases of $\Delta \sigma_{\mathrm{yz}}\left(\Delta \sigma_{\mathrm{cfs}}\right.$ for $\left.\mu^{\prime}=0\right)$ and $\Delta \sigma_{\mathrm{cfs}}$ for $\mu^{\prime}=0.4$. For the case of $\mu^{\prime}=0.6$ (not shown here), the P-zone of stress increase spreads more towards the downdip portion of the slab, and its maximum increase exceeds 9 bars. The location of the 1997 vertical fault, which is shown in Figure $1 \mathrm{~b}$ and indicated by an arrow in Figure $6 a$ and $b$, has some uncertainty in the horizontal direction, and the depth of the fault ranges between 20 and $50 \mathrm{~km}$. The starting point of rupture at about $35 \mathrm{~km}$ and the major part of the fault are surely located within the P-zone of stress increase. Accordingly, it appears that the 1997 earthquake took place within the contour of the maximum stress increase in the P-zone.

It was found that higher velocities and densities of $10 \%$ in the subducting plate enhance the stress changes on the fault (Fig. 3) up to a maximum of about 15\% and also enhance the maximum magnitude of stress increase in the Pzone up to about 10 bars and 5 bars (for $\mu^{\prime}=0.4$ ) along the $a-a^{\prime}$ and $b-b^{\prime}$ profiles, respectively. However, the actual velocity contrast between the oceanic crust overriding the subducting slab and the overlying crust and uppermost mantle does not reach $10 \%$ but seems to be less than $7 \%$ at the depth range of the 1985 thrust fault (Valdes and Meyer, 1996). Thus, the magnitude of the stress changes in and 

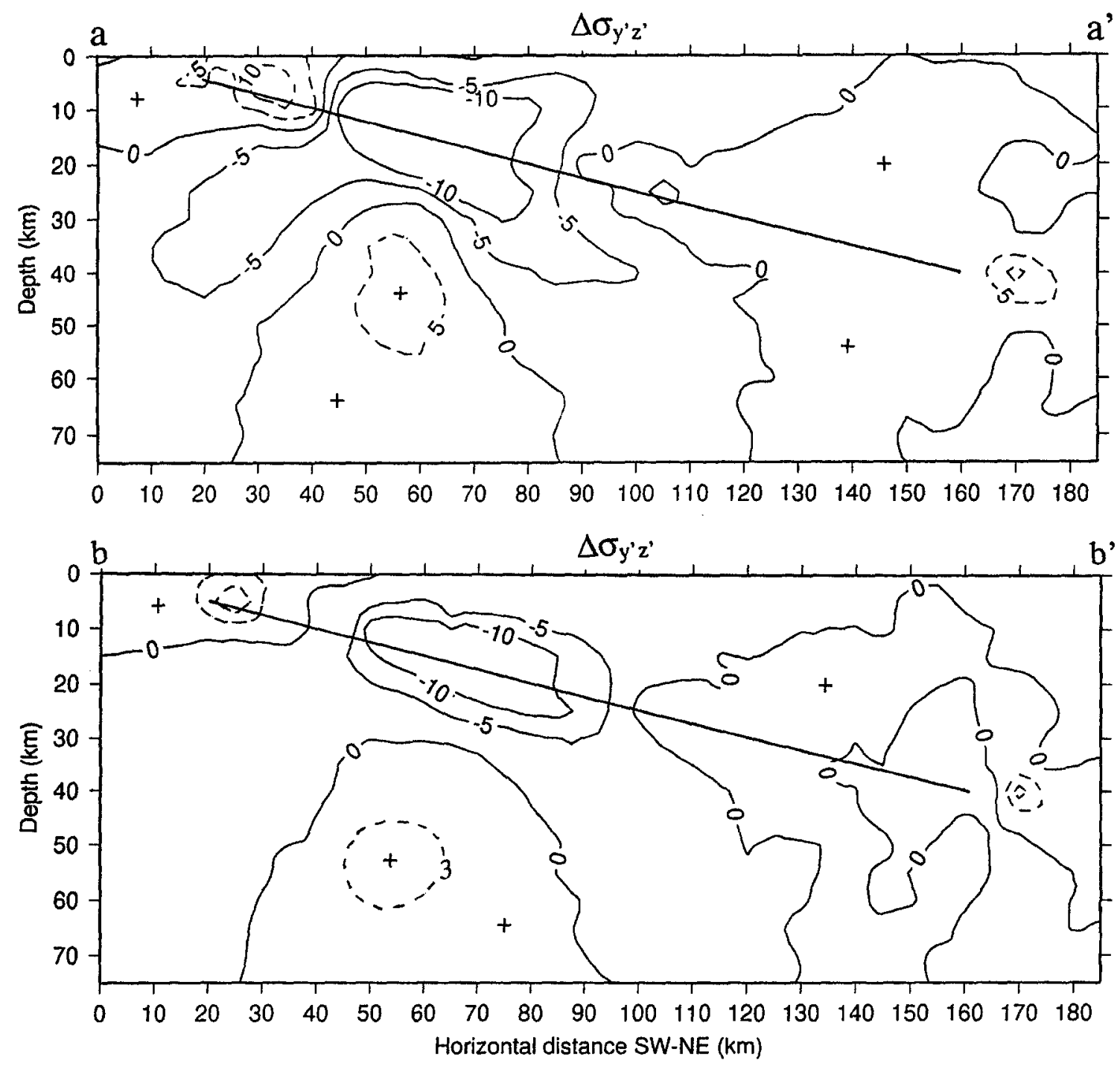

Figure 4. Coseismic changes of shear stress $\Delta \sigma_{y^{\prime} z^{\prime}}$ (in bars) working parallel to the 1985 thrust fault plane, along the two profiles $a-a^{\prime}$ and $\mathbf{b}-\mathbf{b}^{\prime}$ shown in Figures $1 \mathrm{a}$ and 3. The bold oblique line indicates the 1985 dipping fault. Full and broken contours indicate stress decrease and increase, and plus and minus signs denote the zones of stress increase and decrease, respectively. The same explanations apply to Figures 5-7.

around the $\mathrm{P}$-zone is not very sensitive to the velocity structure assumed here and does not significantly affect our estimates. Although it is uncertain whether this order of stress increase is large enough to actually trigger the 1997 normalfaulting event 12 years after the 1985 large thrust earthquake, the magnitude is significantly larger than those so far reported (e.g., Harris, 1998). This may be due to the proximity of the two events, the high stress drop in specific-fault zones, and to the much larger fault extent of the $1985 \mathrm{Mi}-$ choacan earthquake.

Figure 7 shows the calculated coseismic-stress change $\Delta \sigma_{y z}$ due to the 1985 earthquake over the vertical plane including the 1997 fault (fault length, $50 \mathrm{~km}$; fault width, 30 $\mathrm{km}$ at depths between 20 and $50 \mathrm{~km}$ ). Shear stress in the upper-fault section dropped to a considerable extent due to the 1985 event, and it increased up to 4 to 5 bars in the lower half of the fault. The zones of stress increase and decrease appear to be separated by an oblique lobe traversing nearly the middepth of the fault. It is interesting to note that highstress drop and major slip occurred in the lower-fault section during the 1997 earthquake, which suffered a stress increase from the 1985 earthquake; only minor slip and smaller stress drop were observed in the upper-fault zone of the 1997 event, where shear stress has dropped after the 1985 event (Santoyo et al., 1999; Mikumo et al., 1999). This evidence also suggests that the 1997 nearly vertical, normal-faulting earthquake took place under stress transfer from the 1985 thrust earthquake to the subducting plate. 

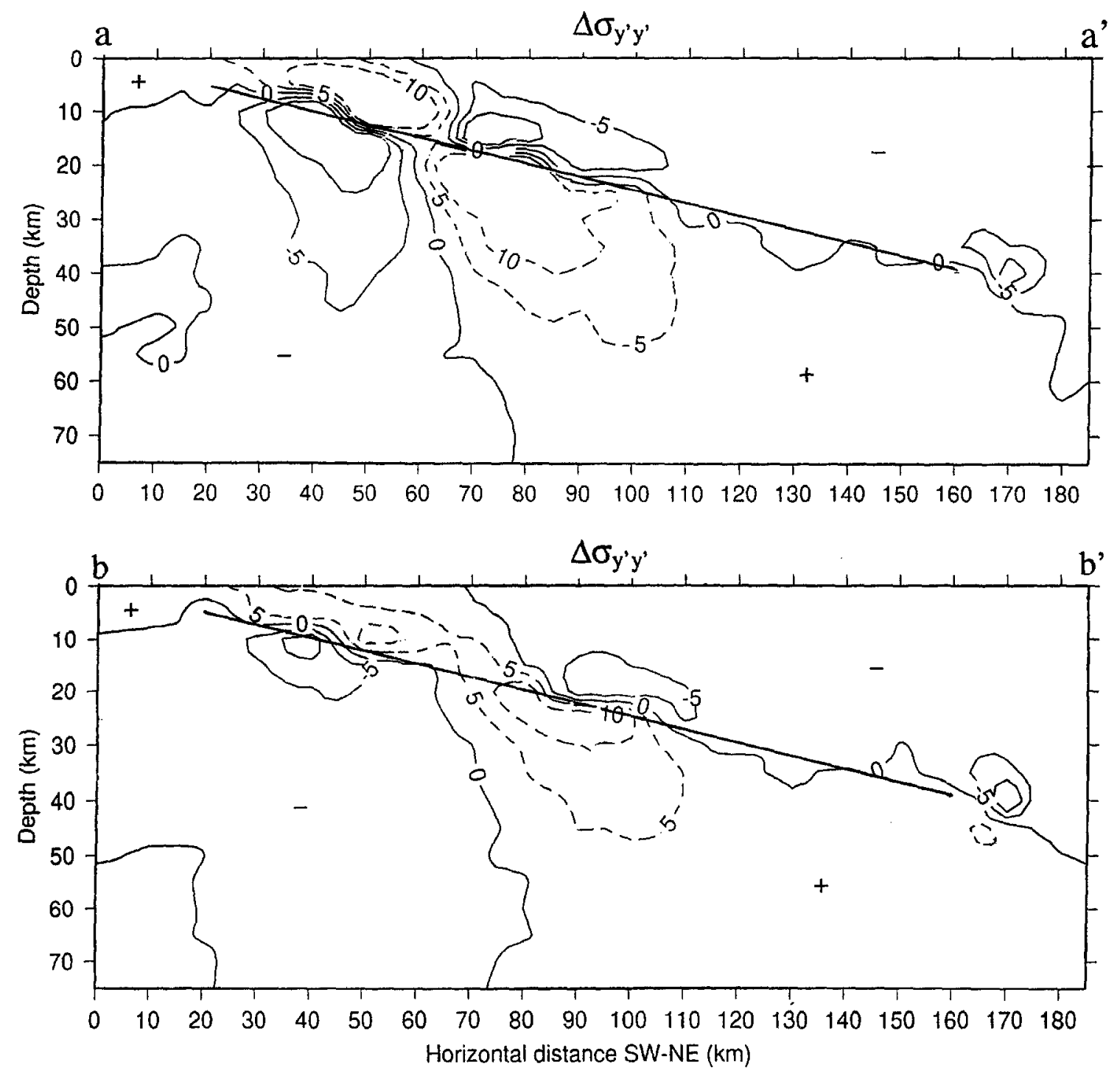

Figure 5. Coseismic changes of compressional stress $\Delta \sigma_{y^{\prime} y^{\prime}}$ (in bars) working parallel to the 1985 thrust fault along the two profiles $a-a^{\prime}$ and $b-b-'$.

\section{Discussion}

Postseismic stress changes that can affect the pattern of coseismic changes and hence the occurrence of the subsequent earthquake may come from possible aseismic slip on the 1985 fault zone and on the updip or the downdip extension of the fault, viscoelastic relaxation of the overlying mantle and the asthenosphere, and loading of extensional stress due to the subduction process. In this article, we do not calculate these changes but qualitatively discuss their possible effects.

Evidence of further aseismic slip on the 1985 fault has not been detected due to the lack of geodetic observations in the area, although it seems likely to have occurred. If it actually occurred on the same fault with a few tens of percent of the coseismic slip, the postseismic increase in the shear stress in the subducting slab would also be of about this order of magnitude. This change would add to the estimated coseismic-stress change, and hence enhance the possibility of occurrence of the 1997 event in this zone. If it occurred on some portion of the updip or downdip segment, a small oblique zone of stress decrease similar to that in Figure 6 would extend into the peripheral zone of coseismic stress increase. This would slightly erode its increase or would almost not affect it.

The viscoelastic stress-relaxation process within a subducted slab during thrust earthquake cycles in coupled subduction zones has been discussed on the basis of simple 1D calculations (Dmowska et al., 1988) and 2D finite-element models (Taylor et al., 1996; Gardi et al., 1999) incorporating Maxwellian viscoelasticity. Their results (e.g. Taylor et al., 1996) indicate that the coseismic changes in the uniaxial stress component $\left(\Delta \sigma_{y^{\prime} y^{\prime}}\right.$ in Figure 5$)$ in the subducting slab just below the thrust zone slowly recovers with time (i.e., 

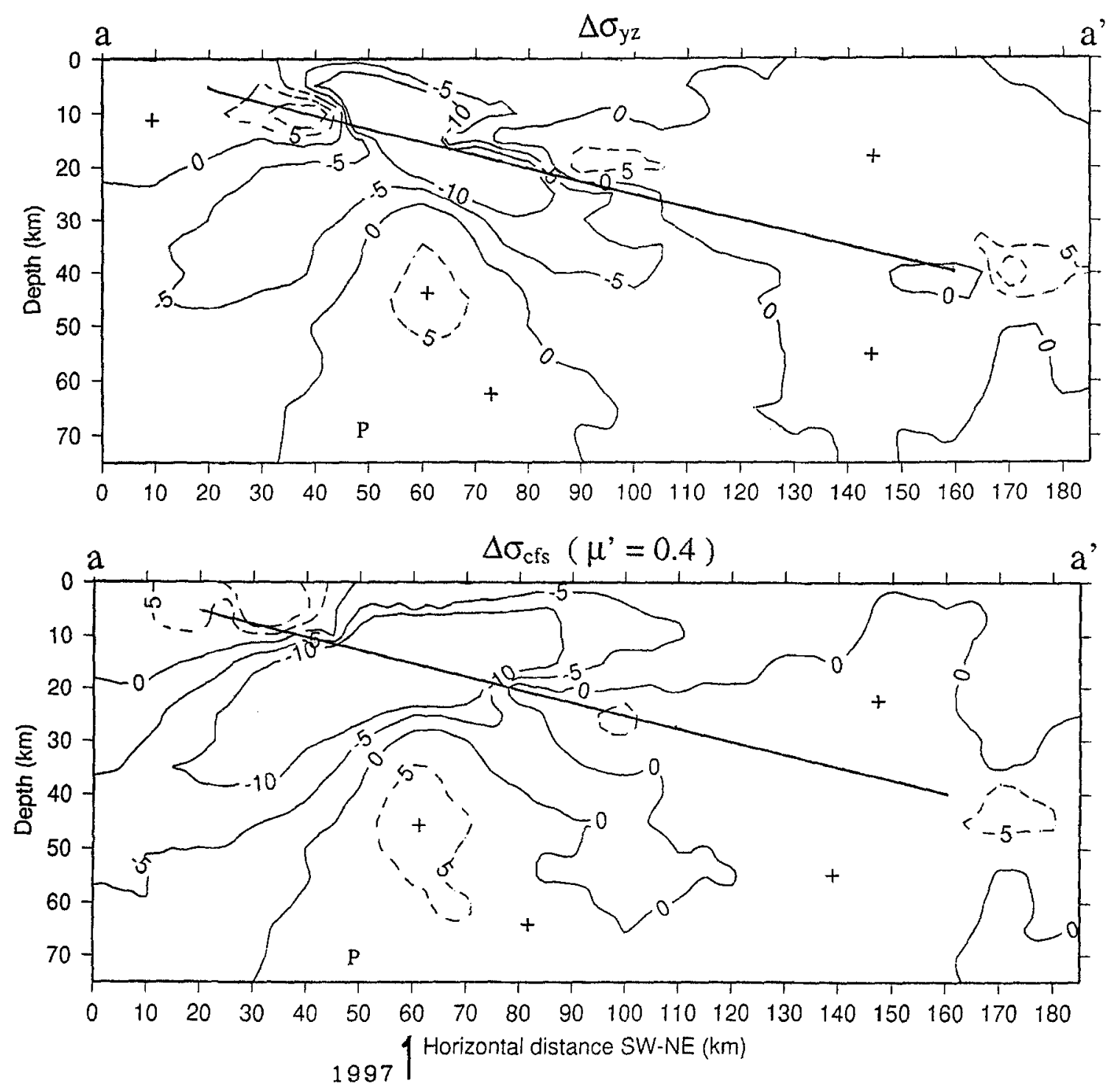

Figure 6. Coseismic changes of the vertical shear stress $\Delta \sigma_{\mathrm{yz}}$ (in bars, top) and the Coulomb failure stress $\Delta \sigma_{\text {cfs }}$ for $\mu^{\prime}=0.4$ (in bars, bottom) due to the 1985 thrust event on two profiles. (a) profile $a-a^{\prime}$, (b) profile $b-b^{\prime}$. An arrow indicates the approximate horizontal location of the 1997 vertical fault. (See also Figure 1b.)

the coseismic, extensional stress change below the updip portion of the thrust plane decreases, and the coseismic, compressional stress change below the downdip portion also decreases with time), but still do not change their sign within the first $15-30 \%$ (corresponding to 12 years) of the recurrence time. This implies that the additional extensional stress caused by the 1985 thrust event was still present in the Pzone at the time of the 1997 earthquake. Moreover, the total stress will be dominated by the slab pull due to the subduction process and, hence, would remain extensional at all times (Dmowska et al., 1988; Taylor et al., 1996). Another possible mechanism that could produce tensile stress in such a shallow-dipping, young oceanic lithosphere as in the Mexican subduction zone would be loading of the overriding continental plate decoupled from the subducting plate (Fujita and Kanamori, 1981; Singh et al., 1985). In any case, this extensional feature would increase $\Delta \sigma_{\mathrm{yz}}$ and $\Delta \sigma_{\mathrm{cfs}}$ in the subducting slab at some depth below the 1985 thrust event.

All the above considerations suggest that the $1985 \mathrm{co}-$ seismic-stress increase at some depth below the middle portion of the subducting slab could be enhanced either by the subduction process or by the loading from the continental plate, and also by postseismic slip, if it actually existed.

It is important, however, to mention that the above explanations do not apply to the two normal-faulting events of 1994 that occurred farther downdip of the 1985 thrust zone and near the bottom of the subducting Cocos plate. These events may possibly be related to the unbending of the slab (e.g. Cocco et al., 1997; Gardi et al., 1999). However, the present calculations might give another explanation as to 

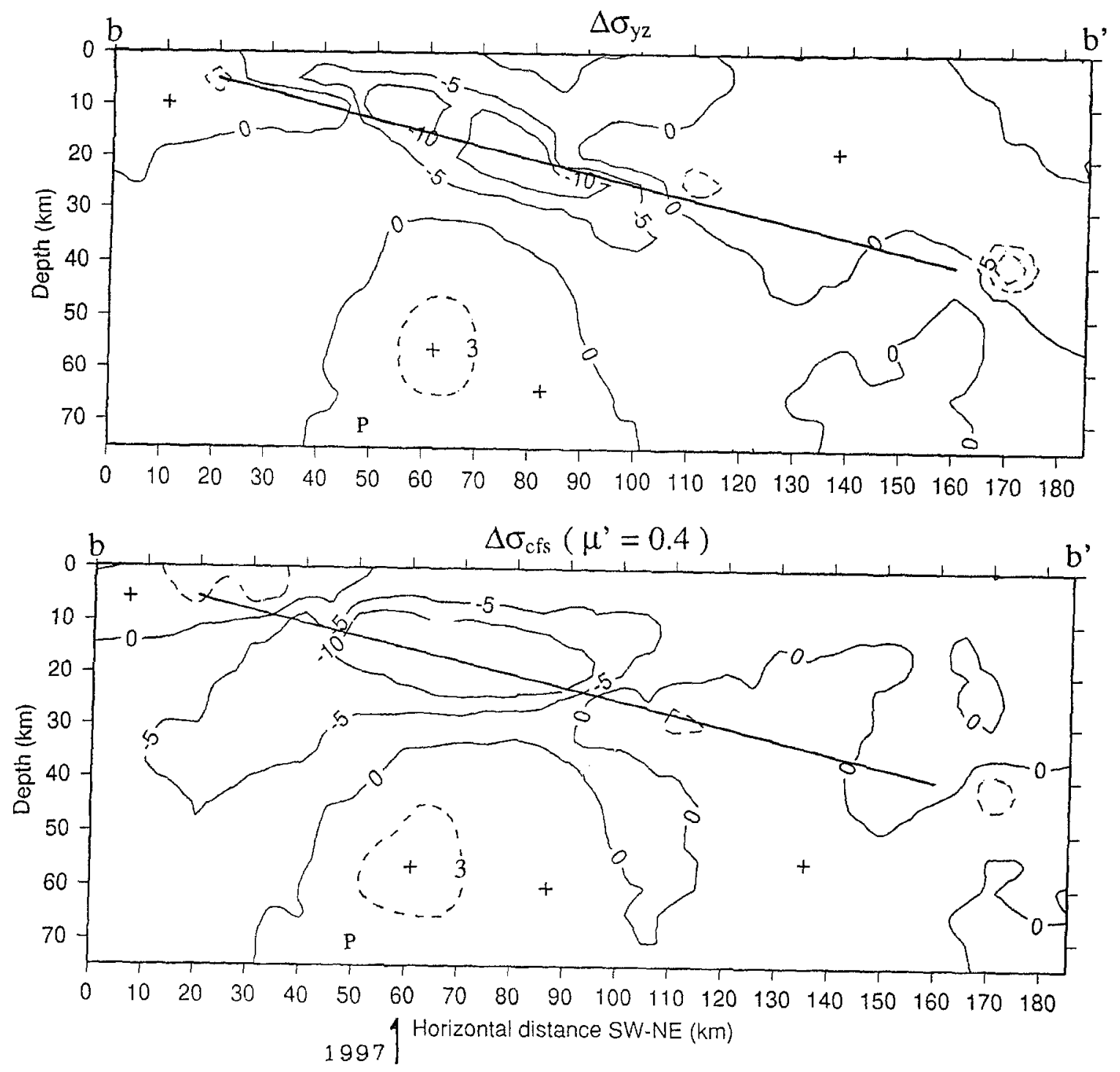

Figure 6. Continued.

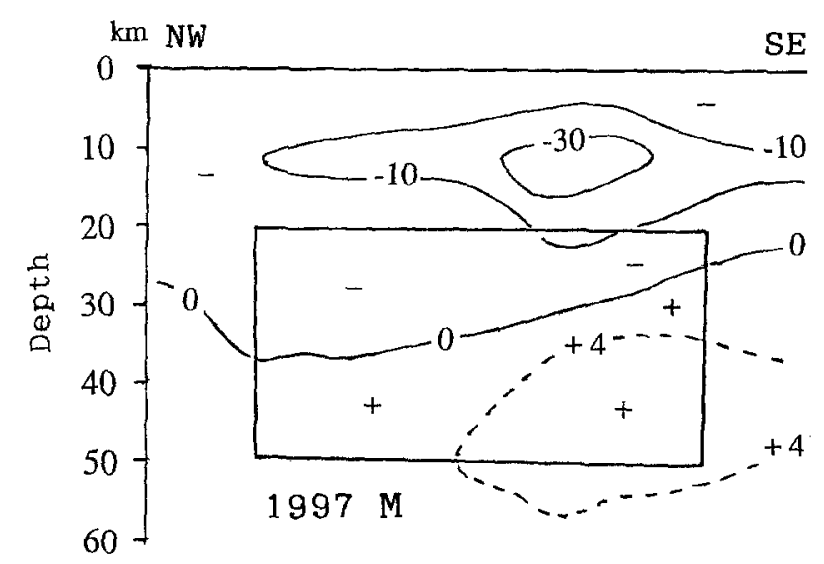

Figure 7. Coseismic changes in the shear stress $\Delta \sigma_{\mathrm{yz}}$ (in bars) due to the 1985 thrust event projected onto the 1997 vertical fault located at depths between 20 and $50 \mathrm{~km}$. why a normal-faulting earthquake could also take place in some other subduction zones near the trench or some far downdip of the thrust plane following a large-thrust earthquake. It is clear from Figure $6 a$ and $b$ that coseismic-stress increase will also occur in these portions of the slab after a large-thrust earthquake.

\section{Conclusions}

We have calculated coseismic stress changes due to the 1985 Michoacan, Mexico, thrust earthquake $\left(M_{\mathrm{W}}=8.1\right)$ in the subducting Cocos plate and in the overlying crust and uppermost mantle to investigate if there is any stress interaction between this thrust earthquake and the 1997 nearly vertical, normal-faulting earthquake that took place just beneath the ruptured fault zone of the 1985 event. The maximum magnitude of stress increase in the vertical-shear stress and in the Coulomb failure stress at depths below $30 \mathrm{~km}$ in 
the middle portion of the subducting plate ranges between 4 and 8 bars $(0.4-0.8 \mathrm{MPa})$. It was found that the 1997 earthquake took place in the zone of maximum coseismic stress increase due to the 1985 event. The dynamic rupture pattern of the 1997 earthquake also appears consistent with that of the stress increase from the 1985 event. Some qualitative considerations on the postseismic-stress change suggest that they may strengthen the coseismic-stress change. All the aforementioned evidence suggests that the 1997 normalfaulting earthquake occurred under stress transfer from the 1985 earthquake to the interior of the subducting Cocos plate.

\section{Acknowledgments}

We wish to thank Hiroo Kanamori for providing us with some information on lithospheric normal-faulting earthquakes in the subduction zones around the globe. Our thanks are extended to Diane I. Doser (Associate Editor), Martin Reyners, and an anonymous reviewer for their constructive comments in improving the manuscript.

\section{References}

Abe, K. (1972a). Lithospheric normal faulting beneath the Aleutian trench, Phys. Earth Planet. Interiors 5, 90-98.

Abe, K. (1972b). Mechanisms and tectonic implications of the 1966 and 1970 Peru earthquakes, Phys. Earth Planet. Interiors 5, 367-379.

Abe, K. (1977). Tectonic implications of the large Shioya-oki earthquake of 1938, Tectonophysics, 41, 269-289.

Christensen, D. H., and T. Lay (1988). Large earthquakes in the Tonga region associated with subduction of the Louisville ridge, J. Geophys. Res. 93, 13367-13389.

Clayton, R., and B. Engquist (1977). Absorbing boundary conditions for acoustic and wave equations, Bull. Seism. Soc. Am. 67, 1529-1540.

Cocco, M., M. J. Pacheco, S. K. Singh, and F. Courboulex (1997). The Zihuatanejo, Mexico, earthquake of 1994 December $10(\mathrm{M}=6.6)$ : source characteristics and tectonic implications, Geophys. J. Int. 131, 135-145.

Dmowska, R., J. R. Rice, L. C. Lovinson, and D. Josell (1988). Stress transfer and seismic phenomena in coupled subduction zones during the earthquake cycles, J. Geophys. Res. 93, 7869-7884.

Eissler, H., and H. Kanamori (1982). A large normal-fault earthquake at the junction of the Tonga trench and Louisville ridge, Phys. Earth Planet. Interiors 29, 161-172.

Freed, A. M., and J. Lin (1998). Time-dependent changes in failure stress following thrust earthquakes, J. Geophys. Res. 103, 24393-24409.

Fujita, K., and H. Kanamori (1981). Double seismic zones and stresses of intermediate depth earthquakes, Geophys. J. Int. 66, 131-156.

Gardi, A., M. Cocco, A. M. Negredo, R. Sabadini, and S. K. Singh (1999). Dynamic modelling of the subduction zone of central Mexico, Geophys. J. Int. (submitted).

Harris, R. A. (1998). Introduction to special section: stress triggers, stress shadows, and implications for seismic hazard, J. Geophys. Res. 103, 24347-24358.

Kanamori, H. (1971). Seismological evidence for a lithospheric normal faulting - the Sanriku earthquake of 1933, Phys. Earth. Planet. Interiors 4, 289-300.

Kausel, E., and J. Campos (1992). The Ms $=8$ tensional earthquake of 9 December 1950 of northern Chile and its relation to the seismic potential of the region, Phys. Earth Planet. Interiors 72, 220-235.

King, G. C. P., R. S. Stein, and J. Lin (1994). Static stress changes and the triggering of earthquakes, Bull. Seism. Soc. Am. 84, 935-953.

Lundgren, P., and E. A. Okal (1988). Slab decoupling in the Tonga arc: the June 22, 1977, earthquake, J. Geophys. Res. 93, 13355-13366.

Lynnes, C. S., and T. Lay (1988). Source process of the great Sumba earthquake, J. Geophys. Res. 93, 13407-13420.

Mendoza, C., and S. Hartzell (1989). Slip distribution of the 19 September 1985 Michoacan, Mexico, earthquake: near-source and teleseismic constraints, Bull. Seism. Soc. Am. 79, 655-669.

Mikumo, T., and T. Miyatake (1993). Dynamic rupture processes on a dipping fault and estimates of stress drop and strength excess from the results of waveform inversion, Geophys. J. Int. 112, 481-496.

Mikumo, T., T. Miyatake, and M. A. Santoyo (1998). Dynamic rupture of asperities and stress change during a sequence of large interplate earthquakes in the Mexican subduction zone, Bull. Seism. Soc. Am. $88,686-702$.

Mikumo, T., M. A. Santoyo, and S. K. Singh (1999). Dynamic rupture and stress change in a normal faulting earthquake in the subducted Cocos plate, Geophys. J. Int. (in press).

Pardo, M., and G. Suarez (1995). Shape of the subducted Rivera and Cocos plates in Southern Mexico: seismic and tectonic implications, J. Geophys. Res. 100, 12357-12373.

Santoyo, M. A., S. K. Singh, and T. Mikumo (1999). Source characteristics of the 11 January, 1997 Michoacan, Mexico, earthquake $(\mathrm{Mw}=7.1)$, Seism. Soc. Am. (to be submitted).

Shiono, K., and T. Mikumo (1975). Tectonic implications of subcrustal normal faulting earthquakes in the western Shikoku region, Japan, $J$. Phys. Earth 23, 257-278.

Singh, S. K., G. Suarez, and T. Dominguez (1985). The Oaxaca, Mexico, earthquake of 1931: lithopheric normal faulting in the subducted Cocos plate, Nature 317, 56-58.

Spence, W. (1986). The 1977 Sumba earthquake series: evidence for slab pull force acting at a subduction zone, J. Geophys. Res. 91, 72257239.

Taylor, M. A. J., G. Zheng, J. R. Rice, D. Stewart, and R. Dmowska (1996). Cyclic stressing and seismicity at strongly coupled subduction zones, J. Geophys. Res. 101, 8363-8381.

UNAM Seismology Group (1986). The September 1985 Michoacan earthquakes: aftershock distribution and history of rupture, Geophys. Res. Lett. 13, 573-576.

Valdes, C., and R. P. Meyer (1996). Seismic structure between the Pacific coast and Mexico City from the Petatlan earthquake $(\mathrm{Ms}=7.6)$ aftershocks, Geofis. Int. 35, 377-401.

Yoshida, Y., K. Satake, and K. Abe (1992). The large normal faulting Mariana earthquake of April 5, 1990 in coupled subduction zone, Geophys. Res. Lett. 19, 297-300.

Instituto de Geofisica

Universidad Nacional Autonoma de Mexico

Ciudad Universitaria, Mexico 04510 D.F., Mexico

E-mail: mikumo@ollin.igeofcu.unam.mx

(T.M., S.K.S., M.A.S.)

Manuscript received 12 April 1999. 